\title{
The impact of non-medical reading on clinician burnout: a national survey of palliative care providers
}

\author{
Daniel Marchalik ${ }^{1}$, Ariel Rodriguez ${ }^{1}$, Amalia Namath ${ }^{1}$, Ross Krasnow ${ }^{2}$, Simone Obara ${ }^{3}$, Jamie \\ Padmore $^{4}$, Hunter Groninger ${ }^{5}$ \\ ${ }^{1}$ Literature and Medicine Track, Georgetown University School of Medicine, Washington, DC, USA; ${ }^{2}$ Department of Urology, MedStar Washington \\ Hospital Center, Washington, DC, USA; ${ }^{3}$ Beth Israel Deaconess Medical Center, Boston, MA, USA; ${ }^{4}$ Office of Academic Affairs, MedStar Health, \\ Washington, DC, USA; ${ }^{5}$ Department of Medicine, Georgetown University Medical Center, Washington, DC, USA \\ Contributions: (I) Conception and design: D Marchalik, J Padmore, S Obara, H Groninger; (II) Administrative support: J Padmore; (III) Provision of \\ study materials or patients: None; (IV) Collection and assembly of data: D Marchalik, A Rodriguez, A Namath; (V) Data analysis and interpretation: \\ D Marchalik, R Krasnow, H Groninger; (VI) Manuscript writing: All authors; (VII) Final approval of manuscript: All authors. \\ Correspondence to: Hunter Groninger, MD. c/o Section of Palliative Care, MedStar Washington Hospital Center, 110 Irving Street NW, Room 2A68, \\ Washington, DC 20010, USA. Email: hunter.groninger@medstar.net.
}

\begin{abstract}
Background: Clinician burnout in hospice and palliative care (HPC) has potentially widespread negative consequences including increased clinical errors, decreased professionalism, decreased staff retention, and decreased empathy. Reading non-medical literature has been associated with increased empathy, but no studies on the effect of reading on burnout have previously been conducted. We wished to assess reading patterns of practicing HPC clinicians and determine associations between non-medical reading and burnout. Methods: Sixteen-item electronic survey regarding reading practices, exposure to non-medical literature, fatigue, quality of life, and burnout symptoms was administered to members of the American Academy of Hospice and Palliative Medicine. Burnout measures of emotional exhaustion and depersonalization were assessed by the validated 2-item Maslach Burnout Inventory. Data were analyzed using descriptive statistics and multivariate regression.
\end{abstract}

Results: Seven hundred nine members responded (15.2\% response rate), of which 129 (18.2\%) met the criteria for burnout, with 117 (16.6\%) meeting the criteria for high emotional exhaustion and 45 (6.3\%) meeting the criteria for high depersonalization. On univariate analysis, burnout was associated with age, reading habits, and fatigue, but not years in practice. On multivariable logistic regression consistent readers had decreased odds of overall burnout compared to inconsistent readers (OR 0.61; 95\% CI, 0.39-0.97, $\mathrm{P}=0.036$ ). This was true across the depersonalization (OR 0.58; 95\% CI, 0.36-0.93, $\mathrm{P}=0.025$ ), but not the emotional exhaustion domain.

Conclusions: Reading non-medical literature on a consistent basis may be associated with a significantly decreased likelihood of burnout, specifically across the depersonalization domain.

Keywords: Palliative; hospice; medical humanities; burnout; compassion fatigue

Submitted Oct 29, 2018. Accepted for publication May 29, 2019.

doi: 10.21037/apm.2019.05.02

View this article at: http://dx.doi.org/10.21037/apm.2019.05.02

\section{Introduction}

Physician burnout compromises the safety and well-being of both patients and physicians. Affecting over half of practicing physicians in the United States, burnout appears to be on the rise (1). A work-related syndrome, burnout exists across three dimensions: emotional exhaustion, depersonalization, and a feeling of a lack of accomplishment (2). The gold standard for measuring burnout is the Maslach Burnout Inventory (MBI), a 22-item questionnaire assessing the condition across 
all three domains (3-5).

The causes of physician burnout are multifactorial and include both systemic and individual (1-3) contributors (6-10). At the same time, physician burnout has been linked to compromised physician well-being, worse patient outcomes, and increased medical errors (11-13). Because of the vast impact of burnout on physicians, patients, and healthcare systems, many recent studies have focused on attempting to identify ways of decreasing burnout across various specialties $(14,15)$. Interventions on both personal and organizational levels have been shown to decrease rates of burnout among physicians (15-17). Some useful strategies to reduce burnout include mindfulness, stress reduction, and small group discussions (15). Hospice and palliative care (HPC) physicians specifically have previously identified physical wellness, professional relationships, talking with others, and hobbies as effective methods to prevent burnout (16).

Though HPC physicians have been shown to have higher rates of burnout compared to other specialties in a study using the AAHPM listserv (62\%), a recent meta-analysis showed an overall burnout rate in palliative care providers to be $17.3 \%(3,18)$. Importantly, even in the aggregate, the study was limited by a low number of responders and data on HPC burnout remain largely lacking. Nevertheless, HPC providers continue to face unique burnout-related pressures including high moral distress stemming from the inability of physicians to act by their ethical beliefs due to institutional restraints as well as the growing shortage of physicians within the specialty (19-22).

Reading non-medical literature such as fiction, poetry, or creative non-fiction has recently been identified as an effective method to decrease stress and improve physician empathy (23-26). In one study, reading non-medical literature has also been found to be protective against burnout in anesthetists and intensive care physicians (17). However, data on the effect of reading non-medical literature to prevent burnout remain generally lacking. With that in mind, we sought to explore the effect of nonmedical literature on burnout in HPC providers.

\section{Methods}

A 16-question electronic survey was administered to attending physicians, fellows, nurse practitioners, physician assistants, pharmacists, social workers, and administrators who specialize in HPC via email using the American Academy of Hospice and Palliative Medicine (AAHPM) member database. The email title was "Humanities in the
Palliative Profession". The survey assessed respondent nonmedical reading habits, self-reported levels of fatigue and burnout, and demographic information. Upon survey completion, respondents were offered the chance to participate in a raffle for a $\$ 150$ Amazon gift card. In accordance with prior studies, fatigue was measured on a linear 10-point scale using a single item with an answer of 7 or above corresponding to fatigue associated with impairment $(27,28)$. Burnout was measured using the previously validated two single-item measure of emotional exhaustion and depersonalization from the Maslach Burnout Inventory (29). The data were collected into a de-identified database using REDCap (30). Institutional review board exemption from the MedStar Health Research Institute was acquired prior to study initiation. The introduction to the study survey clarified to participants that, by participating in the survey, they were also providing consent for their responses to be collected, analyzed, and reported in aggregate.

Participant characteristics included age, undergraduate major, exposure to literature or medical humanities courses during training, preference for fiction $v s$. nonfiction literature, and clinical discipline. Reading quantity was assessed through participant recall of the number of non-medical books read in a typical month. In an effort to effectively compare reading habits to the general population, we paired our reading categories to a recent study by the National Endowment for the Arts (NEA) on reading habits in the United States (31). Within this study, light readers were defined as reading 1-5 books annually, moderate readers as $6-11$ books annually, frequent readers as reading $12-49$ books annually, and avid readers as reading 50 or more books per year (31). Because annual reading habits can be difficult to quantify, we chose to convert NEA data into a month-based 3-point scale in our study: those reading no books or only a part of one book per month on average were considered inconsistent readers, those reading 1-3 books were considered consistent readers, and those reading 4 or more books a month were deemed avid readers.

The study's primary outcome was burnout defined as the presence of high emotional exhaustion, high depersonalization, or both. We used a validated abridged 2-item version of the Maslach Burnout Inventory (MBI) assessing emotional exhaustion ("I feel burned out from my work") and depersonalization ("I have become more callous toward people since I took this job") (32). High emotional exhaustion and high depersonalization were defined by 
responses of "once a week" or more often (29).

We summarized participant characteristics using descriptive statistics. Categorical variables were compared using Fisher's Exact Test and continuous data with the MannWhitney Rank Sum Test. The effect of reading on burnout was evaluated using a multivariable logistic regression model adjusting for age, profession, level of fatigue, and reading level. Secondary analyses were performed to study the effect of reading on emotional exhaustion and depersonalization. NEA data were analyzed with a chi2 test. Tests were twosided, and a $\mathrm{P}$ value $<0.05$ was considered statistically significant. Statistical analysis was performed using Stata 14.2 (StataCorp, College Station, TX, USA).

\section{Results}

Of 4,678 email addresses listed on the AAHPM database, 709 responded (15.2\% response rate). Of 695 respondents who shared their clinical discipline, most consisted of 533 physicians (77\%) and 64 physician fellows (9\%) (Table 1). Of HPC providers surveyed, 129 (18.2\%) met the criteria for burnout with 117 (16.6\%) meeting the criteria for high emotional exhaustion and $45(6.3 \%)$ meeting the criteria for high depersonalization.

When assessing distress in attending physicians and fellows $(\mathrm{n}=595)$, burnout was present in 110 physicians (18.4\%) with $100(16.8 \%)$ and $39(6.5 \%)$ meeting the criteria across the emotional exhaustion and depersonalization domains, respectively.

On univariate analysis, burnout was associated with age, reading habits, and fatigue. Providers exhibiting signs of burnout were younger [median 47 years, interquartile range (IQR) 36-56, versus median 48 years, IQR 38-59, $\mathrm{P}=0.047]$. However, years in practice did not differ significantly between burned-out and not burned-out providers (median 15, IQR 5-25, versus median 15, IQR 5-29, respectively, $\mathrm{P}=0.2)$; nor did preference for fiction, nonfiction, or poetry $(\mathrm{P}=0.41)$. Physicians with burnout were more likely to meet the criteria for fatigue causing impairment $(60.9 \% \mathrm{vs}$. $29.6 \%, \mathrm{P}<0.001)$, and to be inconsistent readers $(45.7 \%$ vs. $33.0 \%, \mathrm{P}=0.015)$. In contrast, providers without burnout were more likely to read consistently $(56.9 \%$ vs. $43.3 \%$, $\mathrm{P}=0.015$, Table 1).

Most respondents reported not having any formal options or programs in literature education available to them during medical school. Overall, choice of undergraduate major prior to working in healthcare, clinical discipline, practice setting, and preference for fiction $v s$. nonfiction literature were not found to significantly influence rates of burnout. For physicians, implementation of formal reading programs or literature courses in medical school also did not influence the rate of burnout.

When compared to national trends established by the NEA, palliative care providers were less likely to be non-readers (only $4.1 \%$ of HPC providers self-identified as non-readers compared to $48.4 \%$ of the general population). A similar number of providers and general population respondents were inconsistent readers (31.2\% vs. 33.8\%). However, HPC providers were much more likely to be consistent readers (54.4\% vs. $13.2 \%$, chi2 $\mathrm{P}$ value $<0.001$, Table 2).

On multivariable logistic regression controlling for age, clinical discipline, and presence of fatigue, consistent readers had decreased odds of overall burnout compared to inconsistent readers (OR 0.61; 95\% CI, 0.39-0.97, P=0.036, Table 3). This was true across the depersonalization (OR $0.58 ; 95 \% \mathrm{CI}, 0.36-0.93, \mathrm{P}=0.025)$, but not the emotional exhaustion domain.

\section{Discussion}

Among attending physicians and fellows who completed the survey, $18.4 \%$ displayed at least one dimension of burnout as determined by the MBI. This level of burnout is consistent with the rates reported in a recent metaanalysis of HPC providers but lower than other surveys of the AAHPM. A 2016 report estimated those rates to be $62 \%$, placing it at the highest end of burnout across various specialties (33). Although admittedly drawing from a very low response rate, another report estimated the degree of HPC provider emotional exhaustion and depersonalization to be $9 \%$ and $4 \%$, respectively, compared to $16.6 \%$ and $7.9 \%$ in our study (34). In a highly understudied population, it is unclear whether this is due to prior overestimates or current underestimates of burnout in HPC providers.

In our analysis, fatigue correlated with burnout across both the emotional exhaustion and depersonalization domains of burnout. Fatigue was present in twice as many physicians who met the burnout criteria than in those who did not (60.9\% vs. $29.6 \%)$, an observation consistent with prior research (35-37). Though prior studies have distinguished between sleepiness and fatigue (37), our study was not designed to measure work hours and sleepiness in HPC providers.

Though other studies have shown burnout rates to be higher in palliative care social workers (38) and nurses $(39,40)$, our analysis showed no difference between 
Table 1 Characteristics of survey respondents*

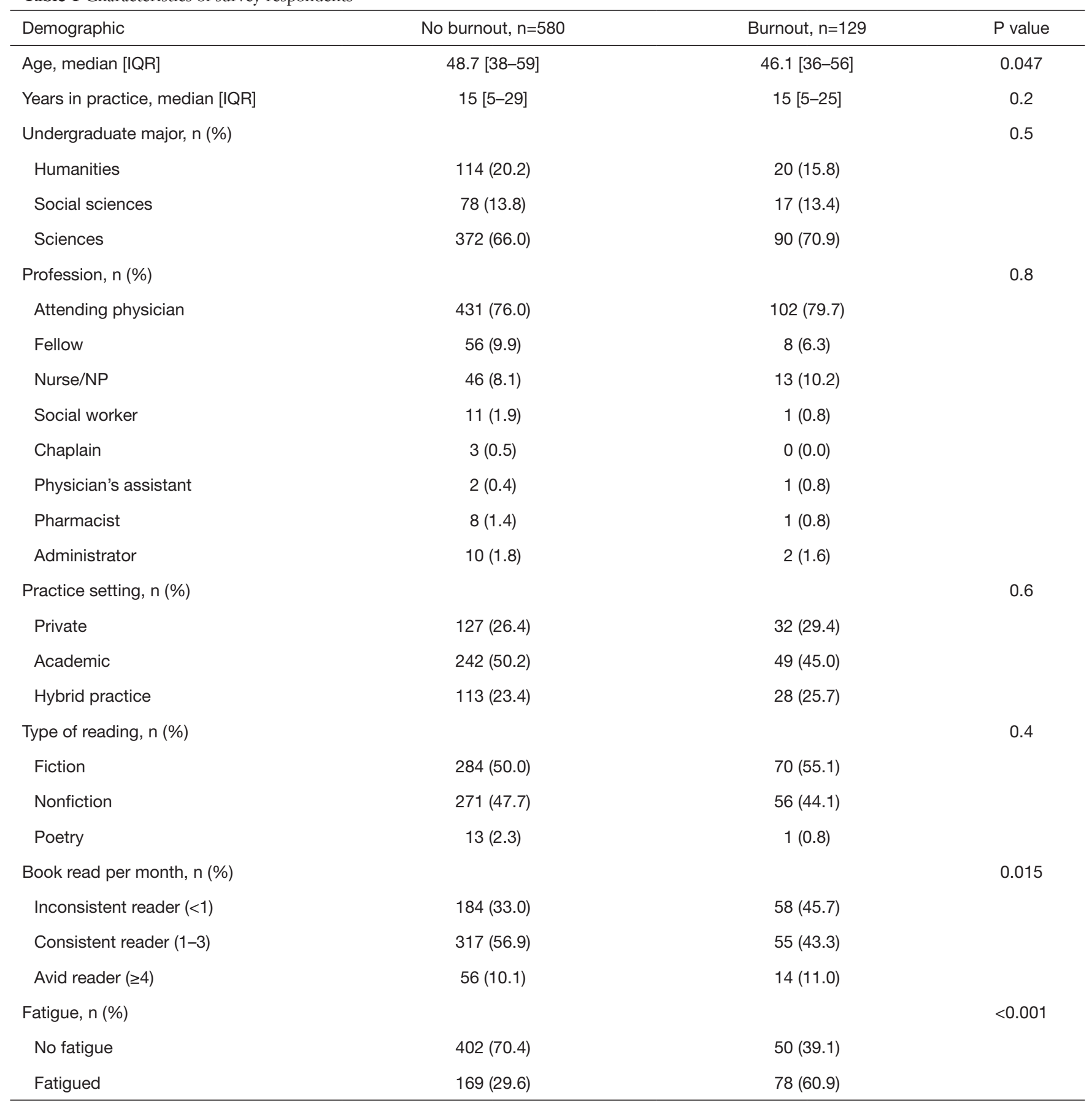

${ }^{*}$, percentages shown are reflective of the specific demographic rather than the total number of respondents.

multidisciplinary clinicians. It is possible that the difference in distress observed in those smaller studies was due to specific program-level conditions and do not reflect the state of the field as a whole. We also failed to show a difference between academic and non-academic practice settings. Though prior studies have showed a higher prevalence of burnout in inpatient hospital settings, the effects of academic practices had not been previously assessed (38). 
Table 2 Comparison of reading activity of AAHPM member survey respondents to general population survey respondents

\begin{tabular}{|c|c|c|c|}
\hline Reading activity & $\begin{array}{l}\text { General population } \\
(\mathrm{NEA}), \mathrm{n}=35,735\end{array}$ & $\begin{array}{l}\text { Palliative care providers } \\
\qquad \text { (AAHPM), } n=609\end{array}$ & $P$ value \\
\hline Non-readers & $48.4 \%$ & $4.1 \%$ & $<0.001$ \\
\hline $\begin{array}{l}\text { Inconsistent (light/moderate) readers, }<12 \text { books per } \\
\text { year } /<1 \text { book per month }\end{array}$ & $33.8 \%$ & $31.2 \%$ & \\
\hline $\begin{array}{l}\text { Consistent (frequent) readers, } 12-49 \text { books per year/1-4 } \\
\text { books per month }\end{array}$ & $13.2 \%$ & $54.4 \%$ & \\
\hline Avid readers, $\geq 50$ books per year $/ \geq 4$ books per month & $4.6 \%$ & $10.2 \%$ & \\
\hline
\end{tabular}

AAHPM, American Academy of Hospice and Palliative Medicine.

Table 3 Multivariable logistic regression model of the association of readership and fatigue with burnout

\begin{tabular}{|c|c|c|c|c|c|c|c|c|c|}
\hline Predictor & \multicolumn{3}{|c|}{ Burnout } & \multicolumn{3}{|c|}{ Emotional exhaustion } & \multicolumn{3}{|c|}{ Depersonalization } \\
\hline Age & 0.99 & $0.97-1.01$ & 0.2 & 0.99 & $0.96-1.01$ & 0.3 & 0.99 & $0.97-1.01$ & 0.2 \\
\hline Medical doctor & 1.03 & $0.57-1.87$ & 0.9 & 1.61 & $0.56-4.67$ & 0.4 & 0.99 & $0.53-1.82$ & 1 \\
\hline Fatigue & 3.69 & $2.41-5.67$ & $<0.001$ & 2.30 & $1.2-4.4$ & 0.012 & 3.60 & $2.31-5.62$ & $<0.001$ \\
\hline Inconsistent reader (<1 book/mo) & & Referent & & & Referent & & & Referent & \\
\hline Consistent reader ( $1-3$ books $/ \mathrm{mo})$ & 0.61 & $0.39-0.97$ & 0.036 & 1.33 & $0.65-2.73$ & 0.4 & 0.58 & $0.36-0.93$ & 0.025 \\
\hline Avid reader ( $\geq 4$ books/mo) & 0.97 & $0.46-2.05$ & 0.9 & 1.30 & $0.39-4.38$ & 0.7 & 1.07 & $0.5-2.27$ & 0.9 \\
\hline
\end{tabular}

Table 4 Comparison of AAHPM membership at-large and our study cohort

\begin{tabular}{lcc}
\hline Demographic & AAHPM & Study cohort \\
\hline Average age & 46 & 46 \\
Provider type & & $75 \%$ \\
Physician & $75 \%$ & $9 \%$ \\
Fellow & $6 \%$ & $12 \%$ \\
Affiliate (nurse, social worker, chaplain) & $11 \%$ & $4 \%$ \\
Other & $4 \%$ & $4 \%$ \\
\hline
\end{tabular}

*, at the time of this study, "Affiliate" is the term employed by AAHPM to designate all clinical disciplines other than physicians. AAHPM, American Academy of Hospice and Palliative Medicine.

Though our study did show that younger providers had a higher rate of burnout—a finding consistent with previously published studies $(40,41)$ - the difference in the mean age was small. At the same time, we observed no difference in the mean year in practice and burnout. Together, our findings point to the fact that the drivers of burnout in HPC may be inherent to the field itself rather than practice setting, provider roles, and seniority.

Our study suggests that HPC providers are more active readers than the general population. Because higher education has been linked to increased likelihood of reading, we believe that this could be due to the greater overall rate of advanced education in the AAHPM cohort (since all HPC providers would have to complete graduate 
training to practice palliative care medicine) (31). As observed in the NEA study, literature reading tended to increase with education, with $81.7 \%$ of graduate degrees recipients reading electively (31). The reading rates also appeared consistent with those previously reported in the medical field. In a survey of medical students in England, $38 \%$ reported reading occasionally, 29\% rarely, and 5\% never reading (42). These rates are not dissimilar to our observation of $31.2 \%$ inconsistent readers and $4.1 \%$ nonreaders.

Our study found that being a consistent reader of nonmedical literature may be protective against the occurrence of burnout. Though data on the effect of reading on burnout are lacking, recent reports have focused on the healing effect of literature on healthcare providers $(17,24,25,43)$. In our study, the primary protective effect of literature was observed across the depersonalization, but not the emotional exhaustion domain. These findings likely speak to the ability of literature, and fiction in particular, to nurture empathy and theory of mind and, in the process, reduce provider callousness toward patients (44-47). At the same time, literature may help build meaning in work and exert a protective effect on work-related distress. This suggests that health organizations and medical schools could benefit from expanding their curricula to include formal reading programs for clinicians. Meanwhile, other initiatives, such as online or specialty-meeting book clubs could facilitate provider reading in groups of peers $(25,48,49)$.

Our study is subject to several limitations. Chief among those is the relatively low response rate of $15 \%$. This is significantly greater than typical response rates from survey research through AAHPM of $5-10 \%$. We are not able to discern numbers of participants who never received the emails or who never opened them; if we were, the true response rate would likely be notably higher. Nevertheless, perhaps more important than the response rate itself, we believe our population to be extremely representative of the AAHPM membership with identical average age and nearly identical provider type breakdown (Table 4). It is certainly possible that our study is limited by selection bias; considering the email survey title, "Humanities in the Palliative Profession," respondents likely have an interest in the humanities and associated disciplines, potentially excluding respondents without similar interests. However, the email's title and introduction prior to survey initiation gave no indication that our primary outcome focused on burnout, suggesting that there was no selection bias regarding burnout. Another limitation inherent in this type of survey is recall bias.

The incidence of burnout among physicians who responded was lower than previous studies have found among HPC physicians. Because little research has previously been done on burnout in HPC providers, our study adds an important data point to this inquiry. However, it is also possible that physicians who are more dedicated readers were more compelled to complete the survey on reading patterns. If our hypothesis were to be accurate then this bias of more readers answering the survey could skew the demonstrated burnout rates to be lower than expected. The abridged 2-question MBI could also underestimate the prevalence of burnout in our cohort.

As with all survey research, the study could be subject to a selection bias in which physicians not experiencing burnout feel less compelled to complete this survey. As such, we would expect the burnout rate to be artificially inflated which appears inconsistent with our current findings. Recall bias could contribute to self-reported reading habits.

\section{Conclusions}

Among HPC clinicians, those who read non-medical literature have been found to have a lower level of burnout than those who did not report being consistent readers. We found that reading non-medical literature on a consistent basis may be associated with a significantly decreased likelihood of burnout, specifically across the depersonalization domain. Based on our findings, healthcare systems and medical schools should consider introducing literature-related opportunities for physicians, trainees, and medical students as a preventative measure again provider burnout. Next steps in this research should include prospective longitudinal studies comparing non-medical reading with medical reading.

\section{Acknowledgments}

None.

\section{Footnote}

Conflicts of Interest: The authors have no conflicts of interest to declare.

Ethical Statement: As described in our Methods, the human 
subjects research oversight institutional review board administrated by the MedStar Health Research Institute reviewed our study protocol and determined it exempt from full IRB review. Study participants were made aware that, by submitting responses to the electronic survey, they were providing consent for individual responses to be collected, analyzed, and reported in aggregate.

\section{References}

1. Shanafelt TD, Hasan O, Dyrbye LN, et al. Changes in Burnout and Satisfaction With Work-Life Balance in Physicians and the General US Working Population Between 2011 and 2014. Mayo Clin Proc 2015;90:1600-13.

2. Maslach C, Jackson SE. Burnout in organizational settings. In: Oskamp S. editor. Applied Social Psychology Annual: Applications in Organizational Settings. Beverly Hills, CA: Sage, 1984.

3. Kamal AH, Bull JH, Wolf SP, et al. Prevalence and Predictors of Burnout Among Hospice and Palliative Care Clinicians in the U.S. J Pain Symptom Manage 2016;51:690-6.

4. Maslach C, Leiter MP. Understanding the burnout experience: recent research and its implications for psychiatry. World Psychiatry 2016;15:103-11.

5. Christina M, Jackson SE. The measurement of experienced burnout. J Organ Behav 1981;2:99-113.

6. Amoafo E, Hanbali N, Patel A, et al. What are the significant factors associated with burnout in doctors? Occup Med (Lond) 2015;65:117-21.

7. Babbott S, Manwell LB, Brown R, et al. Electronic medical records and physician stress in primary care: results from the MEMO Study. J Am Med Inform Assoc 2014;21:e100-6.

8. Ishak WW, Lederer S, Mandili C, et al. Burnout during residency training: a literature review. J Grad Med Educ 2009;1:236-42.

9. Salles A, Lin D, Liebert C, et al. Grit as a predictor of risk of attrition in surgical residency. Am J Surg 2017;213:288-91.

10. West CP, Shanafelt TD, Kolars JC. Quality of life, burnout, educational debt, and medical knowledge among internal medicine residents. JAMA 2011;306:952-60.

11. Tawfik DS, Profit J, Morgenthaler TI, et al. Physician Burnout, Well-being, and Work Unit Safety Grades in Relationship to Reported Medical Errors. Mayo Clin Proc 2018;93:1571-80.

12. Tawfik DS, Sexton JB, Kan P, et al. Burnout in the neonatal intensive care unit and its relation to healthcareassociated infections. J Perinatol 2017;37:315-20.

13. Welp A, Meier LL, Manser T. Emotional exhaustion and workload predict clinician-rated and objective patient safety. Front Psychol 2015;5:1573.

14. Panagioti M, Panagopoulou E, Bower P, et al. Controlled Interventions to Reduce Burnout in Physicians: A Systematic Review and Meta-analysis. JAMA Intern Med 2017;177:195-205.

15. West CP, Dyrbye LN, Erwin PJ, et al. Interventions to prevent and reduce physician burnout: a systematic review and meta-analysis. Lancet 2016;388:2272-81.

16. Swetz KM, Harrington SE, Matsuyama RK, et al. Strategies for Avoiding Burnout in Hospice and Palliative Medicine: Peer Advice for Physicians on Achieving Longevity and Fulfillment. J Palliat Med 2009;12:773-7.

17. Mikalauskas A, Benetis R, Širvinskas E, et al. Burnout Among Anesthetists and Intensive Care Physicians. Open Med (Wars) 2018;13:105-12.

18. Parola V, Coelho A, Cardoso D, et al. Prevalence of burnout in health professionals working in palliative care: a systematic review. JBI Database System Rev Implement Rep 2017;15:1905-33.

19. Shanafelt TD, Sloan JA, Habermann TM. The well-being of physicians. Am J Med 2003;114:513-9.

20. Dzeng E, Colaianni A, Roland M, et al. Moral Distress Amongst American Physician Trainees Regarding Futile Treatments at the End of Life: A Qualitative Study. J Gen Intern Med 2016;31:93-9.

21. Lupu D. Estimate of Current Hospice and Palliative Medicine Physician Workforce Shortage. J Pain Symptom Manage 2010;40:899-911.

22. Hughes MT, Smith TJ. The Growth of Palliative Care in the United States. Annu Rev Public Health 2014;35:459-75.

23. Sklar DP. Health Humanities and Medical Education: Joined by a Common Purpose. Acad Med 2017;92:1647-9.

24. Marchalik D. The Return to Literature-Making Doctors Matter in the New Era of Medicine. Acad Med 2017;92:1665-7.

25. Chisolm M, Azzam A, Ayyala M, et al. What's a book club doing at a medical conference? MedEdPublish 2018;7:8.

26. Mar RA, Oatley K, Djikic M, et al. Emotion and narrative fiction: Interactive influences before, during, and after reading. Cogn Emot 2011;25:818-33.

27. Gudex C, Dolan P, Kind P, et al. Health state valuations from the general public using the visual analogue scale. Qual Life Res 1996;5:521-31.

28. Temel JS, Pirl WF, Recklitis CJ, et al. Feasibility and 
validity of a one-item fatigue screen in a thoracic oncology clinic. J Thorac Oncol 2006;1:454-9.

29. Harris PA, Taylor R, Thielke R, et al. Research electronic data capture (REDCap)--a metadata-driven methodology and workflow process for providing translational research informatics support. J Biomed Inform 2009;42:377-81.

30. Iyengar S, Grantham E, Nichols B, et al. A decade of arts engagement: Findings from the Survey of Public Participation in the Arts, 2002-2012. Washington, DC: National Endowment for the Arts, 2012.

31. West CP, Dyrbye LN, Satele DV, et al. Concurrent validity of single-item measures of emotional exhaustion and depersonalization in burnout assessment. J Gen Intern Med 2012;27:1445-52.

32. West CP, Dyrbye LN, Sloan JA, et al. Single item measures of emotional exhaustion and depersonalization are useful for assessing burnout in medical professionals. J Gen Intern Med 2009;24:1318-21.

33. Kamal AH, Shanafelt TD. Measuring Burnout in Palliative Care: Authors' Reply. J Pain Symptom Manage 2016;52:e2

34. Dréano-Hartz S, Rhondali W, Ledoux M, et al. Burnout among physicians in palliative care: Impact of clinical settings. Palliat Support Care 2016;14:402-10.

35. Low JM, Tan MY, See KC, et al. Sleep, activity and fatigue reported by postgraduate year 1 residents: a prospective cohort study comparing the effects of nightfloat versus traditional overnight on-call. Singapore Med J 2018;59:652-5.

36. West CP, Tan AD, Shanafelt TD. Association of resident fatigue and distress with occupational blood and body fluid exposures and motor vehicle incidents. Mayo Clin Proc 2012;87:1138-44.

37. West CP, Tan AD, Habermann TM, et al. Association of resident fatigue and distress with perceived medical errors. JAMA 2009;302:1294-300.

Cite this article as: Marchalik D, Rodriguez A, Namath A, Krasnow R, Obara S, Padmore J, Groninger H. The impact of non-medical reading on clinician burnout: a national survey of palliative care providers. Ann Palliat Med 2019;8(4):428-435. doi: 10.21037/apm.2019.05.02
38. Koh MY, Chong PH, Neo PS, et al. Burnout, psychological morbidity and use of coping mechanisms among palliative care practitioners: A multi-centre crosssectional study. Palliat Med 2015;29:633-42.

39. Fonseca A, Pereira S, Carvalho AS. Burnout in nurses working in Portuguese palliative care teams: a mixed methods study. Int J Palliat Nurs 2012;18:373-81.

40. Shanafelt TD, Balch CM, Bechamps GJ, et al. Burnout and career satisfaction among American surgeons. Ann Surg 2009;250:463-71.

41. Soler JK, Yaman H, Esteva M, et al. Burnout in European family doctors: the EGPRN study. Fam Pract 2008;25:24565 .

42. Hodgson K, Thomson R. What do medical students read and why? A survey of medical students in Newcastle upon Tyne, England. Med Educ 2000;34:622-9.

43. Gunderman R. For the young doctor about to burn out. The Atlantic 2014.

44. Kidd DC, Castano E. Reading literary fiction improves theory of mind. Science 2013;342:377-80.

45. Marchalik D. Saving the professionalism course. Lancet 2015;385:2346-7.

46. Nash W. Showing that Medical Ethics Cases Can Miss the Point: Rewriting Short Stories as Cases. Lit Med 2018;36:190-207.

47. Charon R. The patient-physician relationship. Narrative medicine: a model for empathy, reflection, profession, and trust. JAMA 2001;286:1897-902.

48. Marchalik D, Jurecic A. Novel remedies. Lancet 2015;386:1223.

49. Claire McDaniel and Daniel Marchalik: Haruki Murakami's The Colorless Tsuluru Tazaki and the Complexity of Grief. Available online: https://blogs. bmj.com/bmj/2016/04/20/claire-mcdaniel-and-danielmarchalik-haruki-murakamis-the-colorless-tsuluru-tazakiand-the-complexity-of-grief/ 